\title{
MENGELOLA WEBSITE SEKOLAH MENGGUNAKAN WORPRESS SMP DARROSTA DAN YAYASAN PENDIDIKAN ISLAM ADDA'WATUL ISLAMIYI
}

\author{
Ana Rusmardiana, Danang Sutrisno, Kursehi Falgenti, Heri Satria Setiawan \\ Informatika, Fakultas Teknik dan Ilmu Komputer, \\ Universitas Indraprasta PGRI
}

\begin{abstract}
Abstrak
Kegiatan abdimas dalam bentuk pembelajaran membangun dan mengelola website menggunakan wordpress ini bertujuan untuk membekali pengurus yayasan Adda'watul Islamiyi, guru, tata usaha dan siswa SMP Darrosta dengan keterampilan mengelola website menggunakan CMS (Content Management System) Wordpress. Diharapkan dengan pembalajaran dan pemberian pelatihan, pihak sekolah yaitu guru, staf maupun siswa SMP Darrosta serta pengurus yayasan Adda'watul Islamiyi mampu mengelola website yang dibangun, serta menjaga website mereka dari gangguan dari eksternal.
\end{abstract}

Kata kunci :pelatihan, wordpress, guru, website, CMS

\begin{abstract}
This abdimas activity in the form of learning to build and manage websites using wordpress aims to equip the management of the Adda'watul Islamiyi foundation, teachers, administration and students of Darrosta Middle School with the skills to manage websites using Wordpress CMS (Content Management System). It is expected that with the lessons and training, the schools, namely teachers, staff and students of Darrosta Middle School and administrators of the Adda'watul Islamiyi foundation are able to manage the website that was built, and maintain their website from external interference.
\end{abstract}

Key words : training, wordpress, teacher, website, CMS

Correspondence author: Ana Rusmardiana, anarusmardiana@gmail.com, Jakarta, Indonesia (i) (5)

This work is licensed under a CC-BY-NC

\section{PENDAHULUAN}

Di era internet saat ini sudah merupakan suatu keharusan bahwa yayasan maupun sekolah perlu memiliki halaman web untuk menyampaikan informasi dan kegiatankegiatan sebagai pertanggung jawaban kepada masyarakat. Namum demikian SMP Darrosta yang berada dalam naungan yayasan pendidikan Adda'watul Islamiyi sampai saat ini belum memilki cukup sumber daya untuk menbangun dan mengelola halaman web. Sementara cukup banyak sekolah yang sudah memiliki web sendiri dan memiliki sumber daya manusia yang cukup terampil dalam membangun dan mengelola web. Halaman web yang dimaksud setidaknya dapat dipergunakan memuat berbagai 
informasi tentang sekolah berikut kegiatannya. Dengan adanya halaman web terutama untuk sekolah akan dapat dimanfaatkan yayasan, guru, calon siswa maupun siswa serta orang tua calon siswa untuk melihat informasi tentang sekolah yang akan menjadi tempat belajar selama 3(tiga) tahun bagi anak-anaknya dan sebagainya.

Di era internet ini SMP Darrosta dan yayasan yang menaunginya belum memanfaatkan teknologi informasi dengan maksimal untuk mendukung aktivitasnya. Perkembangan pengguna internet yang terus meningkat dan tersedianya berbagai layanan diinternet belum dimanfaatkan pihak untuk menyebarkan informasi tentang sekolah dan kegiatan-kegiatan yang dilakukan. Saat ini mitra ingin memanfaatkan layanan web untuk menyebarkan inforamsi tentang sekolah dan kegiatan-kegiatan yang dilakukan. Sekolah juga ingin memperkuat branding sekolah agar lebih dikenal dan difavoritkan sebagai sekolah swasta pilihan utama di kawasan khususnya Jakarta Barat. Guna keberlangsungan pendidikan dan agar dapat beroperasi dengan baik diperlukan halaman web dan dirawat dengan melakukan update berkala serta memasang security tool. Karena tanpa adanya security tool maka website akan mudah di retas dan diganggu oleh pihak luar yang tidak bertanggung jawab.

Oleh karenanya tim abdimas merasa perlu untuk mengadakan pembelajaran pengelolaan website dalam bentuk pelatihan bagi pengurus yayasan dan SMP Darrosta. SMP Darrosta merupakan sekolah swasta yang berada dalam Yayasan Adda'watul Islaamiyi, yang beralamatkan di Jl. Daan Mogot, Km 12, 8 RT 012 RW.13 N0.65, Kalideres Cengkareng, Jakarta Barat. Pendirian sekolah ini berdasarkan SK No. 02 pada tanggal 02 Juni 2008 dan baru mendapat izin operasional pada tanggal 26 Mei 2014 dengan SK .NO.6529/-1.851.58.

Kami berharap pembelajaran maupun pelatihan yang kami sampaikan dapat dikuti oleh operator sekolah dan pihak yayasan agar memiliki keterampilan pembuatan dan pengolahan web yang baik serta dapat memanfaatkan website untuk tujuan positif. Materi utama pelatihan ini adalah mengelola halaman web menggunakan Content Manajemen Sistem (CMS) dari wordpress. Peserta juga mendapatkan pengetahuan setup hosting dan domain untuk sebuah website.

\section{Maksud dan Tujuan}

Adapun tujuan dari kegiatan abdimas ini sebagai salah satu dari tridahrma perguruan tinggi melalui program iptek untuk masyarakat yaitu untuk meningkatkan pemahaman dan pengetahuan masyarakat terutama bagi pengurus yayasan, guru SMP Darrosta beserta tenaga administrasi mengenai keterampilan pembuatan dan pengelolaan website. Dengan memilki keterampilan dan pengetahuan pembuatan dan pengelolaan website diharapakan mereka dapat memperkaya konten web dengan konten positif yang bermanfaat bagi siswa, calon siswa dan orangtua calon siswa yang ingin mendapatkan informasi menyeluruh tentang sekolah SMP Darrosta.

Bagi SMP Darossta, dengan adanya layanan web ini diharapakan dapat menigkatkan citra sekolah dimasyarakat maupun sebagai salah satu cara strategi branding nama sekolah agar lebih dikenal di dunia maya maupun di dunia nyata.

Dengan melaksanakan Pengabdian kepada Masyarakat berupa penyuluhan dan pelatihan ini diharapkan dapat memberikan pengetahuan guna meningkatkan keahlian sumber daya manusia bagi para guru agar lebih menguasai komputer khususnya dalam pembuatan maupun pemeliharaan website sekolah. Target yang diharapkan dari kegiatan pengabdian masyarakat yang kami lakukan di SMP Darrosta dan Yayasan Adda'watul Islaamiyi adalah: 
1. Pengelola yayasan, guru dan staf yayasan, maupun siswa SMP Darrosta memiliki keterampilan dalam membangun sebuah website dan mengelolanya menggunakan CMS wordpress.

2. Pengelola Web memilki pengetahuan dalam mengelola sebuah website dan memanfaatkan security tool untuk menjaga website dari gangguan pihak luar yang tidak diharapkan.

Tim Abdimas akan menawarkan solusi pembuatan halaman web interaktif dan responsif. Halaman web yang fleksibel yang tidak hanya bisa diakses dari browser di perangkat komputer tapi juga dapat diakses dari berbagai perangkat mobile seperti tablet dan handphone. Halaman website SMP Darrosta dan yayasan ini di buat menggunakan wordpress. Worspress selama ini dikenal sebagai media blog. Namun dalam perkembanganya wordpreess banyak juga dipakai untuk membangun halaman website. Banyak orang memilih wordpreess karena kesederhanaanya dan mudah dalam konfigurasinya. Tim abdimas mengangap wordpress cocok dipakai sebagai CMS (Content Mamagement System) untuk halaman website SMP Darrosta. Selain membuat halaman website diadakan juga pelatihan mengelola halaman website. Seluruh peserta dari SMP Darosta dan pengurus yayasan mendapatkan materi pembelajaran dasar berupa keterampilan pembuatan dan pengelolan website yang dirancang untuk pemula.

\section{Realisasi Kegiatan}

Kegiatan pengabdian masyarakat ini dilaksanakan pada ruang labolatorium SMP Darrosta yang beralamatkan di Jl. Daan Mogot, Km 12.8 RT 012/RW.13 N0.65, Cengkareng Timur, Jakarta Barat. Kegiatan pelaksanaannya dilakukan pada hari Senin tanggal 26 Nopember 2018. Peserta terdiri dari guru, staf tata usaha, beberapa siswa SMP Darrosta serta beberapa orang yang merupakan pengurus Yayasan Adda"watul Islamiyi

\section{METODE PELAKSANAAN}

Metode pelaksanaan adalah metode pelatihan, yaitu pemberian materi sekilas tentang Microsoft Office yaitu Word dan Excel, wordpress, cpanel berikut nama-nama domainnya. Dalam kegiatan pengabdian ini selain menjelaskan juga diberikan contoh bagaimana aplikasi tersebut dapat dilakukan, tidak hanya melalui komputer namum juga dapat di diakses dari berbagai perangkat mobile seperti tablet dan handphone

Pelaksanaan kegiatan pengabdian masyarakat ini dilakukan kedalam tiga tahap, yaitu tahap persiapan, pelaksanaan, dan evaluasi. Berikut mi adalah tahapan pelatihan yang dilakukan:

1. Tahap Persiapan

a. Survei calon mitra

Tim yang terdiri dari 4 (empat ) orang melakukan survei keberapa lokasi yaitu yayasan yang berada didaerah Jakarta Barat atau berbatasan dengan wilayah Tangerang dan yayasan yang berada didaerah Jakarta Timur atau berbatasan dengan wilayah Bekasi Selatan. Untuk pelaksanaannya dibagi dalam 2 (dua) kelompok dalam persurveian tersebut agar lebih efisien baik dalam wakru dan biaya..

b. Pemantapan dan penentuan mitra

Dari hasil survei tersebut, tim melakukan pertemuan untuk mendiskusikan penentuan mitra yang akan dipilih, dan berdasarkan dari hasil musyawarah serta 
kesediaan mitra maka tim memilih sebuah yayasan yang memiliki sekolah yaitu Yayasan Adda'watul Islamiyi dengan kepemilikan sekolahnya yaitu SMP Darrosta. Yayasan dan sekolah tersebut letaknya berdampingan yang lokasinya berada di wilayah Daan Mogot, Cengkareng Jakarta Barat.

c. Sosialisasi

Selanjutnya tim kembali mengunjungi Yayasan Adda"watul Islamiyi untuk menjelaskan materi pelatihan. Kemudian, tim mengunjungi SMP Darrosta yang merupakan sebagai tempat untuk pelaksanaannya yaitu di ruang labolatorium SMP Darrosta untuk melihat sarana maupun prasarana yang diperlukan guna mendukung pelaksanaan pengabdiaan masyarakat ini. Dari hasil pertemuan tersebut, mitra dalam hal ini pengurus maupun pengelola sekolah, juga minta diberikan pelatihan tentang microsoft office yaitu word dan excel selain tentang Web.

2. Tahap Pelaksanaan Pelatihan

Tahap pelaksanaan pelatihan diawali beberapa persiapan terlebih dahulu agar memudahkan dalam pelatihan sehingga berlangsung lancar. Pelatihan dilaksanakan pada hari Senin tanggal 26 Nopember 2018 dalam 3 (tiga) sesi. Pelaksanaan ini dilakukan hanya satu hari dikarenakan lokasi tempat mitra berada didaerah rawan banjir dan juga atas dasar pertimbangan kondisi cuaca yang terjadi di bulan Nopember-Desember tahun ini. Pelaksanaan dimulai dari jam 8.30 sampai dengan jam 17.30 WIB dengan waktu jeda dua kali.

Untuk sesi pertama, sesuai permintaan mitra, maka diberikan pelatihan microsoft word dan excel berikut contoh-contohnya. Kemudian dilanjutkan pada materi tentang instansi dan pengetahuan dasar wordpress, cpanel beserta nama-nama domain. Disesi selanjutnya hingga akhir peserta mengikuti workshop membangun dan mengelola web dengan wordpress. Dilanjutkan dengan praktek membuat halaman web secara langsung. Halaman web tersebut dapat ditampilkan di browser.

3. Tahap Evaluasi

Evaluasi kegiatan dilakukan pada selama proses dan akhir pelatihan, meliputi aspek pencapaian tujuan pelatihan dan juga penyelenggaraan pelatihan. Evaluasi proses dan hasil dilakukan dengan tanya jawab dan observasi. Sedangkan evaluasi aspek penyelenggaraaan pelatihan dilakukan dengan pemberian latihan yang akan dikerjakan peserta.

\begin{tabular}{|c|c|c|}
\hline \multicolumn{3}{|c|}{ TAHAP PERSIAPAN } \\
\hline Survei calon mitra & $\begin{array}{c}\text { Penentuan dan } \\
\text { memantapkan mitra }\end{array}$ & Sosialisasi \\
\hline \multicolumn{3}{|c|}{ TAHAP PELAKSANAAN } \\
\hline microsoft office & Wordpress & Praktek \\
\hline \\
\hline
\end{tabular}

Gambar 2. Diagram Alur Kegiatan Pengabdian Masyarakat 


\section{HASIL DAN PEMBAHASAN}

Program pengabdian kepada masyarakat dilaksanakan pada tanggal 26 November 2018 dimulai dari jam 07.30 -17.45 dilabolatorium SMP Darrosta sebanyak 25 (duapuluh lima) peserta terdiri dari pengurus Yayasan Adda'watul Islamiyi, guru, tata usaha dan beberapa siswa SMP Darrosta Daan Mogot, Jakarta Barat.

Pada dasarnya program pelaksanaan pengabdian masyarakat dimaksudkan untuk memperkenalkan dan sekaligus pembelajaran agar trampil dan mahir dalam pembuatan dan mengelola web guna kepentingan sekolah. Dari mitra yaitu Yayasan Adda'watul Islamiyi maupun SMP Darrosta meminta pula untuk memberikan pembelajaran tentang microsoft office yaitu word dan excel

Pencapaian dalam pelaksaan kegiatan pengabdian masyarakat ini adalah membangun kepercayaan diri dalam berkreasi membangun desain website sesuai dengan keinginan dan kepentingan yayasan maupun sekolah, dalam hal ini adalah Yayasan Adda'watul Islamiyi dan SMP Darrosta. Diharapkan mereka yang terlibat dapat mengoperasikan dan dapat memperkaya konten web dengan konten-konten yang positif dan dapat lebih tekun menggali lebih dalam lagi dalam pengelolaan website.

Dari awal mulai pelaksanaan kegiatan pelaksanaan pengabdian sampai dengan penutup belum dinemukan hambatan yang berat sehingga seluruh kegiatan pengabdian dapat berjalan dengan baik dan sesuai dengan yang diharapkan. Hal ini merupakan pencapaian yang diperoleh dikarenakan dukungan maupun antusias para peserta yang cukup baik dengan keingintahuan dan mempraktekannya serta didukung pula oleh fasilitas yang ada.

Adapun beberapa materi yang diberikan antara lain :

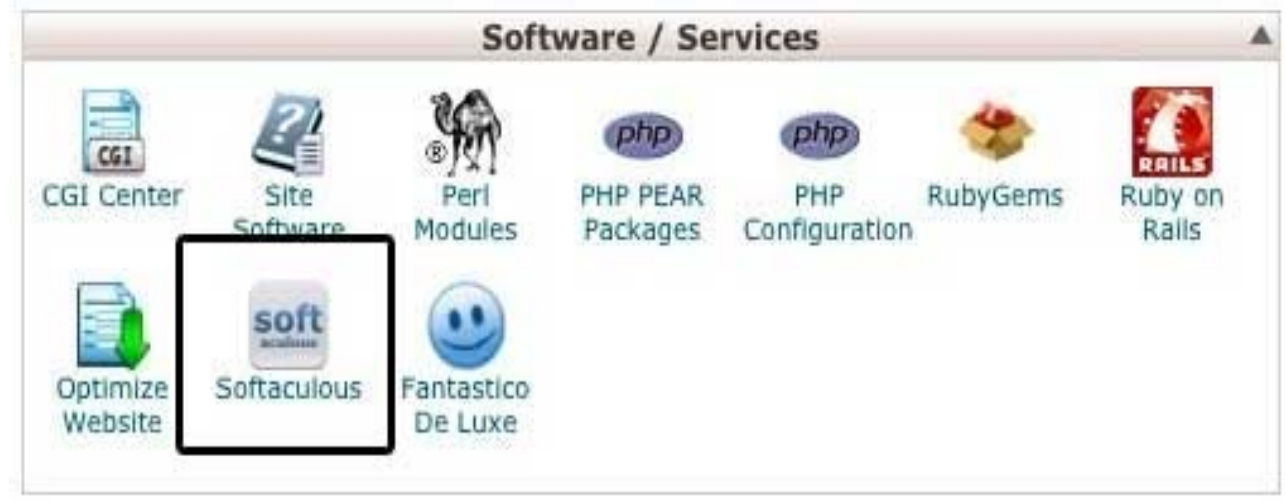

Gambar 3. Softaculous icon

Sumber : https://www.centerklik.com/tutorial-cara-install-wordpress-lengkap/ 
Mengelola Website Sekolah Menggunakan Worpress SMP Darrosta dan Yayasan Pendidikan Islam Adda'watul Islamiyi (Ana Rusmardiana, Danang Sutrisno, Kursehi Falgenti, Heri Satria Setiawan) | 101

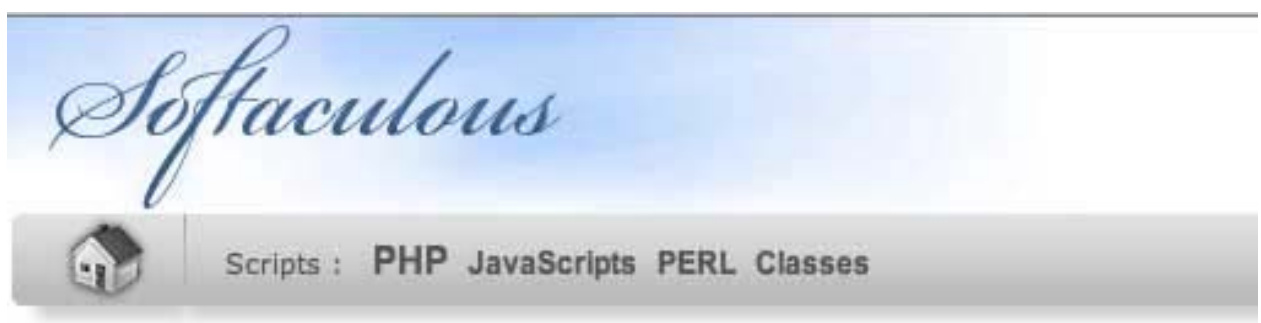

Blogs
Serendipity
Open Blog
b2evolution
LifeType
WordPress
Nurlenis

Gambar 4. Sofftaculous wplink

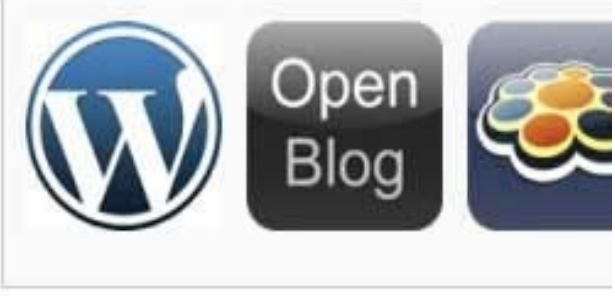

Sumber : https://www.centerklik.com/tutorial-cara-install-wordpress-lengkap/

WordPreSS is a state-of-the-art publishing platform with a focus on aesthetics, web standards, and u: and priceless at the same time.

More simply, WordPress is what you use when you want to work with your blogging software, not fight it.

WordPress started in 2003 with a single bit of code to enhance the typography of everyday writing and with few grown to be the largest self-hosted blogging tool in the world, used on hundreds of thousands of sites and seen

The GPL from the Free Software Foundation is the license that the WordPress software is under.

Version : 3

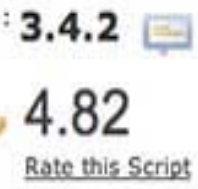

Read R

Rate this Script

Gambar 5. Softaculous wp install

Sumber : https://www.centerklik.com/tutorial-cara-install-wordpress-lengkap/ 


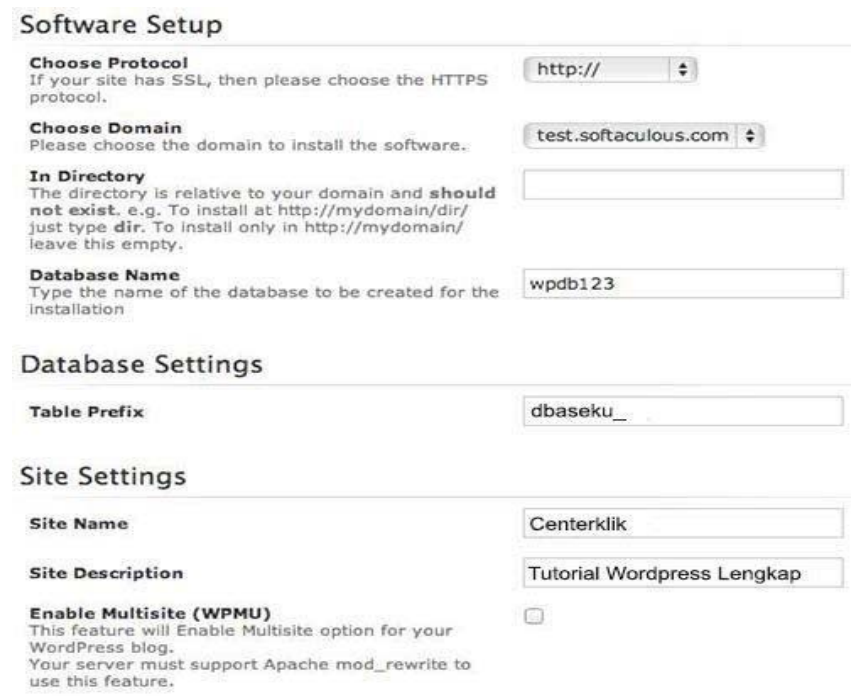

Gambar 6. Softaculous wpsetup

Sumber : https://www.centerklik.com/tutorial-cara-install-wordpress-lengkap/

Dengan aplikasi ini, guru maupun pihak yayasan dapat membuat sendiri web yang mereka butuhkan. Selain materi ini juga diberikan materi Microsoft Office guna mendukung pembuatan web. Secara keseluruhan peserta dapat menerima materi yang diberikan dengan baik.

Berikut adalah beberapa foto kegiatan abdimas yang berlangsung sehari penuh, dari sambutan, pengisian materi berupa penyuluhan dan pelatihan hingga acara penutup.

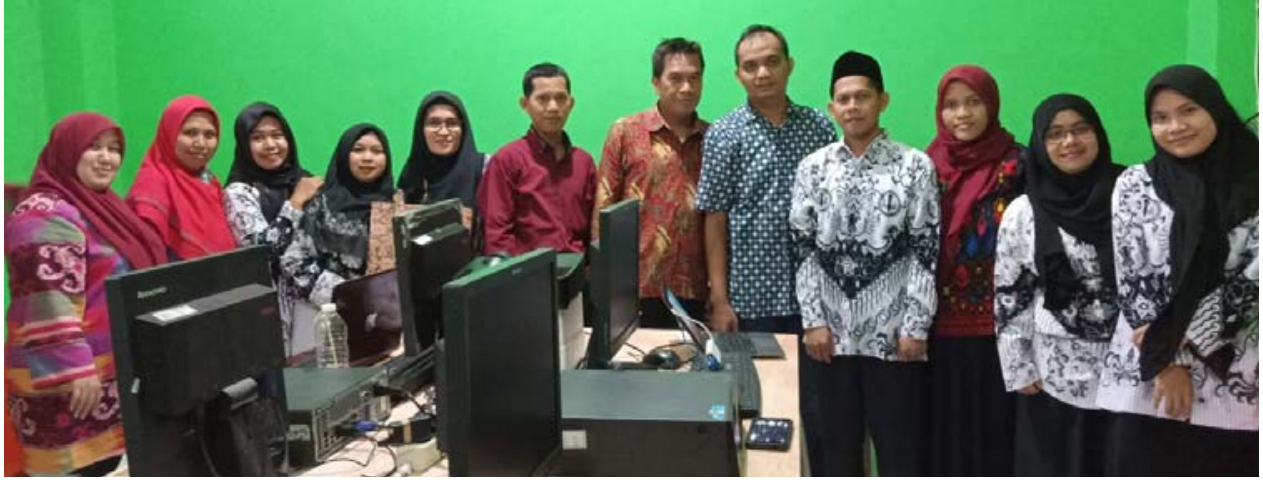

Gambar 7. Foto bersama dengan peserta Abdimas

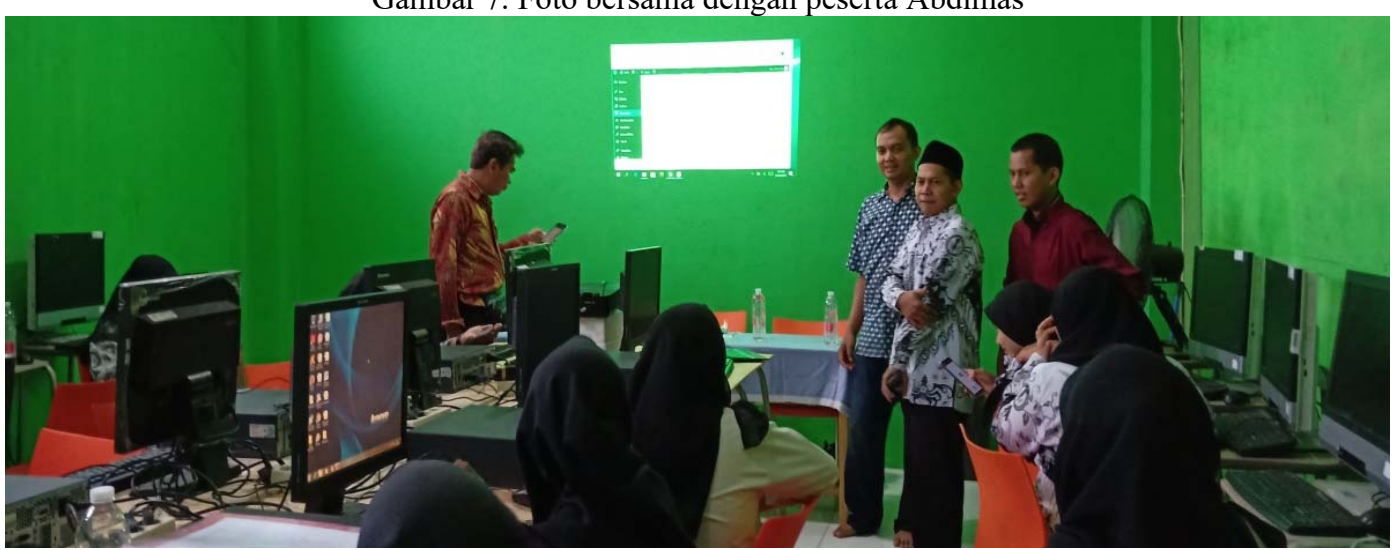

Gambar 8. Foto kegiatan Abdimas 
Sesuai dengan usulan yang diajukan dalam pengabdian masyarakat yang kami lakukan yaitu pembelajaran website menggunkan wordpress maka langkah selanjutnya adalah dengan terus memantau website SMP Darrosta untuk memantau dan memberikan masukan atas perkembangan pengelolaan website tersebut. Dan kepada para seluruh peserta, tim membuka kesempatan atas pertanyaan-pertanyaan yang diajukan via email. Dengan demikian pengembangan website-website yang diciptakan dapat terus kami pantau perkembangannya dan tim memberi masukan agar website yang diciptakan dapat berfungsi semaksimal mungkin.

\section{SIMPULAN}

Content Management System (CMS) adalah aplikasi web yang berisikan template untuk mengelola isi halaman web secara mudah. Penggunaan CMS tidak memerlukan pengetahuan pemrograman web yang handal karena proses instalasi dan cara penggunaannya sudah user friendly. Secara umum WordPress didisain untuk diinstall di server web pribadi, maupun di akun hosting yang dapat diakses secara komput, yang akan memberikan pengaturan yang lengkap pada situs. Tidak seperti layanan hosting pihak ketiga manapun, dapat mengakses dan memodifikasi apapun yang terkait dengan situs, jika memang membutuhkannya. WordPress merupakan salah satu CMS populer, yang dapat digunakan sebagai blog atau website pribadi, membuat berbagai macam situs seperti e-learning, e-commerce, situs sebuah perusahaan, dan lain-lain. WordPress dikembangkan dengan 2(dua) cara, yang pertama pengembangan dilakukan pada lingkungan wordpress.com dan yang kedua pada lingkungan wordpress.org. Jika kita pengguna biasa yang kurang mengerti database dan bahasa pemrograman, sebaiknya menggunakan wordpress.com. Walaupun domain yang digunakan untuk fasilitas yang gratis ini menggunakan domain tambahan.wordpress.com, tapi kita bisa mengupgradenya menjadi domain tanpa tambahan.wordpress.com dengan fasilitas berbayar.

Adapun saran untuk kegiatan ini berdasarkan hasil diskusi tim pelaksana dengan pihak mitra, diharapkan adanya pelatihan lanjutan dengan variasi yang berbeda guna memenuhi kebutuhan proses belajar mengajar sehingga materi yang diperoleh dapat dikuasai secara mendalam dan menyeluruh. Harus banyak pengecekan ulang terhadap program aplikasi supaya tidak terjadinya error, dan sering-sering berlatih untuk menjadi lebih ahli hingga sangat menguasai segala setingan yang ada di wordpress.

\section{DAFTAR PUSTAKA}

https://id.wikipedia.org/wiki/WordPress, diunduh tanggal 14Juli 2018

https://www.centerklik.com/tutorial-cara-install-wordpress-lengkap/, diunduh tanggal 15 Juli 2018

https://idcloudhost.com/panduan/mengenal-softaculous/, diunduh tanggal 15 Juli 2018 